\title{
SENSING THE FRACTAL STRUCTURES IN THE WAVE PROCESSES: SEA SURFACE WIND WAVES
}

\author{
A. A. Svinarenko \\ Odessa National Polytechnical University, Odessa
}

\begin{abstract}
SENSING THE FRACTAL STRUCTURES IN THE WAVE PROCESSES: SEA SURFACE WIND WAVES

A. A. Svinarenko

On the basis of wavelet analysis and multifractal formalism it has been carried out an analysis of fractal structures in the wave processes (sea surface wind waves). The corresponding fractals dimensions are lying in the interval [0,7-0,9].
\end{abstract}

Key words: sensing, fractals, sea surface wind waves

\section{Анотація \\ ДЕТЕКТУВАННЯ ФРАКТАЛЬНИХ СТРУКТУР У ХВИЛЬОВИХ ПРОЦЕСАХ: ВІТРОВІ ХВИЛІ НА МОРСЬКІЙ ПОВЕРХНІ}

\section{А. А.Свинаренко}

Виконано аналіз фрактальних структур у хвильових процессах (вітрові хвилі на морській поверхні) на підставі вейвлет-аналізу та мультіфрактального формалізму. Відповідний спектр фрактальних розмірностей лежить у інтервалі [0,7-0,9].

Ключові слова: детектування, фрактали, вітрові хвилі

\section{Аннотация \\ ДЕТЕКТИРОВАНИЕ ФРАКТАЛЬНЫХ СТРУКТУР В ВОЛНОВЫХ ПРОЦЕССАХ: ВЕТРОВЫЕ ВОЛНЫ НА МОРСКОЙ ПОВЕРХНОСТИ}

\section{А. А. Свинаренко}

Выполнен анализ фрактальных структур в волновых процессах (ветровые волны на морской поверхности) на основе вейвлет-анализа и мультифрактального формализма. Соответствующий спектр фрактальных размерностей лежит в интервале [0,7-0,9].

Ключевые слова: детектирование, фракталы, ветровые волны

In last years it is of a great importance the experimental and theoretical studying of the nonlinear dynamical systems with aim to discover the fractal features and elements of dynamical chaos (c.f.[1-17]). One of the effective approaches to solving such a problem is the multifractal and wavelet analyses. The fundamentals of and application information on the continuous wavelet transformbased method of multifractal analysis are presented in ref.[2-5]. An extension of the concept of multifractals to irregular functions through the use of wavelet transform modulus maxima and potential and limitations of the multifractal formalism in the study of non-stationary processes and short signals 
are in details considered in these references. Especial attention is turned to the multifractality loss effects in the dynamics of different types of systems. In ref. [6] the mechanisms responsible for anomalously high acoustic nonlinearities in multi-phase, defected, and structurally inhomogeneous media are summarized, and nonlinear diagnostics - a fast growing applied area of recent years - is reviewed in terms of its methods and applications. A review of fundamental results on the manifestation of fractal structure in wave processes is presented in [1]. Elastic properties are considered, together with the dispersion of fractal materials, their distribution density, and the shape of wave functions of their localized elastic oscillations, namely fractons. Examples of their application to the explanation of amorphic properties of solids are presented in ref.[1] too. Some patterns of the wave scattering and radiation by fractal structures are examined. Principal methods of random signal analysis are described to reveal different fractal structures associated with these signals and data on the wave field fractal properties are widely discussed in literature. One of the attractive examples of the fractal structures in the wave fields is the fractal ones in the wind waves on the sea surface.

As it is indicated in many references (c.f. [1]) here it is possible an effect of the rays chaos.

It has been defined that the fractal features are available in the shape of the disturbed sea surface as for determinative as random waves. In many papers (c.f. [1-5]) the flow exponential spectra of the wind waves with exponent $11 / 3$ and 4 for gravitate waves are used (for capillary waves it is equal to $17 / 6$ ). In fact, here the rang of scales of the fractal behavior is limited by the distortion correlation radius. It is important to note that a scattering of the waves on the sea surface can be represented as a scattering on the fractals. In paper of Elgar and Mayer-Kress (see refs. in [1]) an another approach is used in studying the fractal properties of the distortion. In fact a dimension of the attractor in the phase space is defined by the Tachens algorithm. It is shown that the surface distortion is not governed by finite dimension dynamical system with a strange attractor. In papers of Zaslavsky et al (c.f. [5]) the fractal properties of the sea surface have been considered on the scales which are more than the distortion correlation radius. In particular, on the basis of analyzing the aero-photo images it has been found the fractality in distribution of the zones for waves falling $(d=0,5)$. In paper by Naugolnyh-Zosimov [19] the fractal properties of the sea surface have been considered too and the laser scanning locator measurements of distribution of the mirror dots along space-temporal line, defined by the vessel running. The cited measurements were carried out in the tropical Atlantic in the opened ocean, where the tropical passate provided the stationary developed distortion during several days. In fact, multi hours data for intensity of the capillary ripple are received. In fig. 1 it is shown realization of the initial spatial spectrum for measured values, namely, the initial spectrum of the large scaled changing intensity of the capillary-gravitational ripple according to the laser scanning data [19].

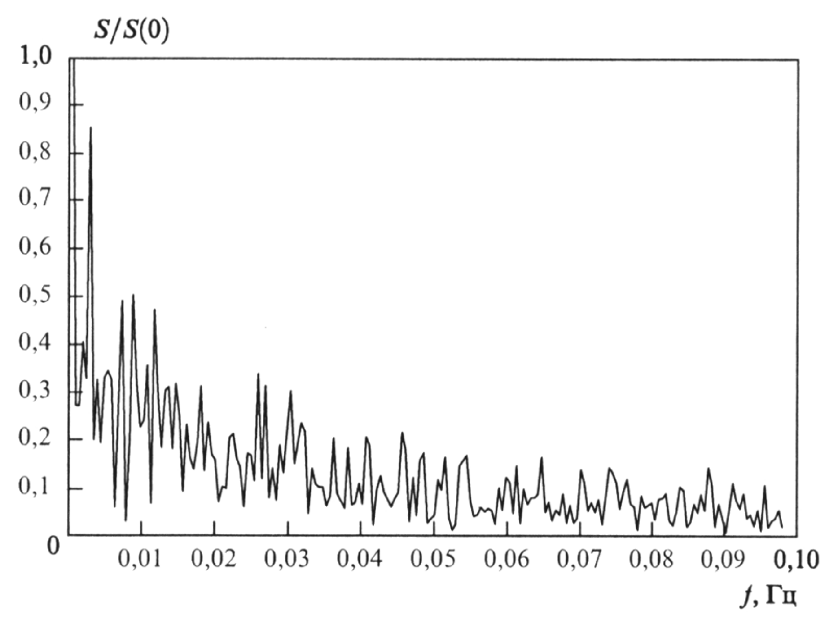

Fig.1. The initial spectrum of the large scaled changing intensity of the capillary-gravitational ripple according to the laser scanning data [19]. In fact a number of reflections under scanning a surface by the thin laser flux (the vessel velocity is $8 \mathrm{~m} / \mathrm{s}$; frequency $1 \mathrm{Gz}$ is corresponding to spatial scale $8 \mathrm{~m}$ )

In our paper we have carried out multifractal analysis of some patterns of the wave scattering, in particular, non-linear dynamical effects in the indicated wave processes. Our analysis of the fractal structures in the wind waves on the sea surface shows that the corresponding fractals dimensions spectrum is found and lying in the interval $[0,7-$ $0,9]$.

Let us further consider wavelet analysis and multi-fractal formalism, following refs. [10-16]. Since last decades, many scientists use the new powerful tool based on the wavelet decomposition for analyzing various signals. At present, the family of analyzing function dubbed wavelets is being increasingly used in problems of pattern recognition; in processing and synthesizing various signals; in analysis of images of any kind (X-ray picture of a kidney, an image of mineral, etc.); for study of tur- 
bulent fields, for contraction (compression) of large volumes of information, and in many other cases. Wavelets are fundamental building block functions, analogous to the sine and cosine functions. Fourier transform extracts details from the signal frequency, but all information about the location of a particular frequency within the signal is lost. At the expense of their locality the wavelets have advantages over Fourier transform when nonstationary signals are analyzed. Here, we use non-decimated wavelet transform that has temporal resolution at coarser scales.

The dilation and translation of the mother wavelet $\Psi(t)$ generates the wavelet as follows: $\Psi_{j, k}(t)=$ $2^{j / 2} \Psi\left(2^{j} t-k\right)$. The dilation parameter $j$ controls how large the wavelet is, and the translation parameter $k$ controls how the wavelet is shifted along the $t$-axis. For a suitably chosen mother wavelet $\Psi(t)$, the set $\left\{\Psi_{j, k}\right\}_{j, k}$ provides an orthogonal basis, and the function $f$ which is defined on the whole real line can be expanded as

$$
f(t)=\sum_{k=-\infty}^{\infty} c_{0 k} \varphi_{0, k}(t)+\sum_{j=1}^{J} \sum_{k=-\infty}^{\infty} d_{j k} \psi_{j, k}(t),
$$

where the maximum scale $J$ is determined by the number of data, the coefficients $c_{0 k}$ represent the lowest frequency smooth components, and the coefficients $d_{j k}$ deliver information about the behaviour of the function $f$ concentrating on effects of scale around $2^{-j}$ near time $k \cup 2^{-j}$. This wavelet expansion of a function is closely related to the discrete wavelet transform (DWT) of a signal observed at discrete points in time. In practice, the length of the signal, say $n$, is finite and, for our study, the data are available monthly, i.e. the function $f(t)$ in Eq. (1) is now a vector $f=\left(f\left(t_{1}\right), \ldots, f\left(t_{n}\right)\right)$ with $t_{i}=i / n$ and $i=$ $1, \ldots, n$. With these notations, the DWT of a vector $f$ is simply a matrix product $d=W f$, where $d$ is an $n \mathrm{Y}$ 1 vector of discrete wavelet coefficients indexed by 2 integers, $d_{j k}$, and $W$ is an orthogonal $n \cup n$ matrix associated with the wavelet basis. For computational reasons, it is simpler to perform the wavelet transform on time series of dyadic (power of 2) length. One particular problem with DWT is that, unlike the discrete Fourier transform, it is not translation invariant. This can lead to Gibbs-type phenomena and other artefacts in the reconstruction of a function. The non-decimated wavelet transform (NWT) of the data $\left(f\left(t_{1}\right), \ldots, f\left(t_{n}\right)\right)$ at equally spaced points $t_{i}=i / n$ is defined as the set of all DWT's formed from the $n$ possible shifts of the data by amounts $i / n ; i=1, \ldots, n$. Thus, unlike the DWT, there are $2^{j}$ coefficients on the $j$ th resolution level, there are $n$ equally spaced wavelet coefficients in the NWT: $d_{j k}=n^{-1} \sum_{i=1}^{n} 2^{j / 2} \psi\left[2^{j}(i / n-k / n)\right] y_{i}, k=0, \ldots, n-$ 1 , on each resolution level $j$. This results in $\log _{2}(n)$ coefficients at each location. As an immediate consequence, the NWT becomes translation invariant. Due to its structure, the NWT implies a finer sampling rate at all levels and thus provides a better exploratory tool for analyzing changes in the scale (frequency) behaviour of the underlying signal in time. These advantages of the NWT over the DWT in time series analysis are demonstrated in Nason et al [12]. As in the Fourier domain, it is important to assess the power of a signal at a given resolution. In order to reach this goal, a time-domain model for encapsulating localized scale activity was proposed by Nason et al. An evolutionary wavelet spectrum (EWS) quantifies the contribution to process variance at the scale $j$ and time $k$. From the above paragraphs, it is easy to plot any time series into the wavelet domain. Another way of viewing the result of a NWT is to represent the temporal evolution of the data at a given scale. This type of representation is very useful to compare the temporal variation between different time series at given scale. To obtain the results, smooth signal $S_{0}$ and the detail signals $D_{j}$ $(j=1, \ldots, J)$ are

$$
\begin{gathered}
S_{0}(t)=\sum_{k=-\infty}^{\infty} c_{0 k} \varphi_{0, k}(t) \\
\text { and } D_{j}(t)=\sum_{k=-\infty}^{\infty} d_{j k} \psi_{j, k}(t) .
\end{gathered}
$$

The fine scale features (high frequency oscillations) are captured mainly by the fine scale detail components $D_{J}$ and $D_{J-1}$. The coarse scale components $S_{0}, D_{1}$, and $D_{2}$ correspond to lower frequency oscillations of the signal. Note that each band is equivalent to a band-pass filter. Further we use the Daubechies wavelet (db15) as mother wavelet. This wavelet is biorthogonal and supports discrete wavelet transform. Using a link between wavlets and fractals, one could make calculating the multi-fractal spectrum. Homogemeous fractals are described by single fractal dimnesion $\mathrm{D}(0)$. Non-homogeneous or multifractal objects are described by spectrum $D(q)$ of fractal dimensions or multifractal spectrum A problem of its calculation reduces to definition of singular spectrum $\mathrm{f}(\alpha)$ of measure $\mu$. It associates Hausdorff dimansion and singular indicator $\alpha$, that allows calculating a degree of singularity: $\mathrm{N}_{\alpha}(\varepsilon)=\varepsilon^{-\mathrm{f}(\alpha)}$. Below we use a formalism, which allows defining spectra of singularity and fractal dimension without using 
standard Legandre transformations. This idea at first used in ref.[8]. Wavelet transformation of real function $\mathrm{F}$ can be also defined as:

$$
\mathrm{W}_{\Psi}[\mathrm{F}](\mathrm{b}, \mathrm{a})=(1 / \mathrm{a}) \int_{-\infty}^{+\infty} F(x) \Psi\left(\frac{x-b}{a}\right) d x
$$

where paraneter $b$ denotes shift in space; parameter defines a space scale. The analyzing splash $\Psi$ has to be localized as in space as on frequency characteristics. The most corect way of estimate of the function $\mathrm{D}(\mathrm{h}), \mathrm{f}(\alpha)$ is in analysis of changing a dependence of distributiob function $\mathrm{Z}(\mathrm{q}, \mathrm{a})$ on modules of maximums of the splash-transfers under scale changes:

$$
\mathrm{Z}=\sum_{i=1}^{N(a)}\left(\omega_{i}(a)\right)^{q}
$$

where $\mathrm{I}=1, \ldots, \mathrm{N}(\mathrm{a}) ; \mathrm{N}(\mathrm{a})$ is a number of localized maximums of transformation $\mathrm{W}_{\psi}[\mathrm{F}](\mathrm{b}, \mathrm{a})=($ for each scale $\mathrm{a}$, where function $\mathrm{x}$ is considering; function $\omega(\mathrm{a})$ can be defined in terms of coefficients of the splash-transformations as:

$$
\omega_{i}(a)=\max \left|W_{\substack{\Psi \\\left(x, a^{\prime}\right) \in L \\ a^{\prime}<a}}[F]\left(x, a^{\prime}\right)\right|,
$$

where $l_{i} \in L(a) ; L(a)$ is a set of such lines, which make coupling the splash-transformation coefficient maximums (they reach or make cross-secting a level, which is corresponding to scale a) In limit $\mathrm{a} \rightarrow 0^{+}$the distribution function $\mathrm{Z}(\mathrm{q}, \mathrm{a})$ manifestes behaviour, corrsponding to degree law: $\left.Z(q, a) \sim a^{\tau(\mathrm{q}}\right)$ . To calculate the singularity spectrum, a canonical approach can be used and based on such functions:

$$
\mathrm{h}(\mathrm{a}, \mathrm{q})=\frac{1}{Z(a, q)} \frac{\partial Z(a, q)}{\partial q},
$$

where $\quad \frac{\partial Z}{\partial q}=\sum_{i=l}^{N(a)} \omega_{i}(a)^{q} \ln \omega_{i}(a)$,

$$
D(a, q)=q h(a, q)-\ln Z(a, q) .
$$

Spectra $D(q)$ and $h(q)$ are defined by standard way: :

$$
\mathrm{D}(\mathrm{q})=\lim _{a \rightarrow 0} \frac{D(a, q)}{\ln a}, \mathrm{~h}(\mathrm{q})=\lim _{a \rightarrow 0} \frac{h(a, q)}{\ln a} .
$$

We have applied the wavelet and multifractal formalism to analysis of the fractal features in the wave processes on example of the wind waves on the sea surface (data from [19]) using the PC numerial complex "Geomath" (c.f.[15]). The numerical estimates have shown that the fractals dimensions are lying in the interval $[0,7-0,9]$. Our calculation confirms the universal conclusion regarding availability of the fractal features for distortion in large scales to a weak wave turbulence for waves with non-decay spectrum. In fact speech is about a model, which describes a growth and stationary spectra of the wave distortion.

Acknowledgement. The author would like to thank Prof. A. Glushkov for invaluable advices and useful critical comments.

\section{References}

1. Zosimov V V, Lyamshev L M, Fractals in wave processes, Physics Uspekhi. - 1995. - Vol.38. - P.347380 .

2. Schertzer D., Lovejoy S., Fractals: Physical Origin and Properites. Ed.L.Peitronero, pp.71-92, Plenum Press, N-Y. (1990).

3. Pavlov A.N., Anishchenko V. .S., Multifractal analysis of complex signals//Physics Uspekhi. - 2007. Vol.177. - P. 859- 876.

4. Likhtenberg A., Liberman M., Regular and stochastic dynamics, Mir, Moscow, (1994).

5. Zaslavsky G.M., Stochasticity of dynamical systems, Nauka, Moscow (1998).

6. Rudenko O.V., Giant nonlinearities in structurally inhomogeneous media and the fundamentals of nonlinear acoustic diagnostics methods// Physics Uspekhi . - 2006. - Vol.176. - P.77-95..

7. Vedenov A.A., Ezhov A.A., Levchenko E.B., Nonlinear systems with memory and functions of neuron ensambles, In: Non-linear waves. Structure and bifurcations Eds Gaponov-Grekhov A.V., Rabinovich M.I., pp.53-69, Nauka, Moscow (1987).

8. Ezhov A.A., Knizhnikova L.A., Levchenko E.B., Chaotic oscillations in system of autogenerators// Izv.Vuzov. Ser.Phys. 36, pp.1167-1169 (1991).

9. Glushkov A.V., Thomas-Fermo model of multibody oscillator//Izv.Vuzov. Ser.Phys. 37, pp.41-47 (1992).

10. Svinarenko A.A., Regular and chaotic dynamics of multi-oscillator dynamical systems//Photoelectronics, 11, pp.81-84 (2002).

11. Glushkov A.V., Ambrosov S.V., Ignatenko V.M., Prepelitsa G.P. Stochastic instability of multioscillator systems and highly excited atoms in electromagnetic field and chaotic dynamics of diatomic molecules in resonance high-intensity IR field // Proc. V Int. Conf. On Atomic and Molecular Physics. - Berlin (Germany). - 2001. - P.A313.

12. Daubechies I., Ten Lectures on Wavelets. Philadelphia: SIAM (1992).

13. Morlet J., Arens G., Fourgeau E. and Giard D., Wave propagation and sampling theory// Geophysics. 1982. - Vol.47. - p.203-236.

14. Nason G., von Sachs R., Kroisand G. Wavelet processes and adaptive estimation of the evolutionary wavelet spectrum // J. Royal Stat. Soc. - 2000. Vol. B-62. - P. 271-292. 
15. Glushkov A.V., Khokhlov V.N., Svinarenko A.A., Bunyakova Yu.Ya., Prepelitsa G.P., Wavelet analysis and sensing the total ozone content in the earth atmosphere: Mycros technology "Geomath"//Sensor Electr. and Microsys.Techn. 2(3),pp.51-60 (2005).

16. Glushkov A.V., Khokhlov V.N., Tsenenko I.A. Atmospheric teleconnection patterns: wavelet analysis// Nonlin. Proc.in Geophys. - 2004. - V.11,N3. P.285-293.

17. Loboda N.S., Stochastic statistical modelling of the irrigation and man-made effects on hydrological systems and water resources// Environm. Inf.Arch. 2003. - Vol.1. - P.267-273.

18. Serbov N.G., Svinarenko A.A., Wavelet and multifractal analysis of oscillations in system of couled autogenerators in chaotic regime// Photoelectronics. - 2006 . - N15. - P.27-30.

19. Naugol'nyh K.A., Zosimov V.V., Chaos: An interdisciplinary journal of nonlinear science. - 1994. Vol.4. - P.21-28. 